Review

\title{
Electrochemical Methods Based on Molecularly Imprinted Polymers for Drug Detection. A Review
}

\author{
Alina Adumitrăchioaie ${ }^{\#}$, Mihaela Tertiș ${ }^{\#}$, Andreea Cernat, Robert Săndulescu, Cecilia Cristea ${ }^{*}$ \\ Analytical Chemistry Department, Faculty of Pharmacy, Iuliu Haţieganu University of Medicine and \\ Pharmacy, 4 Pasteur St., 400349 Cluj-Napoca, Romania \\ *E-mail: ccristea@ umfcluj.ro \\ \# Authors with equal contribution
}

doi: $10.20964 / 2018.03 .75$

Received: 15 December 2017 / Accepted: 21 January 2018 / Published: 5 February 2018

\begin{abstract}
Molecular imprinting of polymers is a state of the art procedure for producing artificial biomimetic receptors with high selectivity towards the selected molecules. Compared to the biological receptors, molecularly imprinted polymers are more stable, easy to prepare, and can be used under harsh conditions, these being the main reasons why their use in chemical and bioanalytical applications has been gaining in interest in the last decades. The main steps in molecular imprinted polymer synthesis from the selection of the reagents to the choice of the polymerization method are summarized. Furthermore, the binding mechanisms between the analyte and the molecules of the monomer during the electrochemical polymerization process and the molecularly imprinted polymer during the detection process, as well the detection techniques are discussed. All discussions present a critical point of view of the authors and are focused on drug detection.
\end{abstract}

Keywords: molecular imprinted polymers; electrochemical sensors; drug analysis

\section{FULL TEXT}

(C) 2018 The Authors. Published by ESG (www.electrochemsci.org). This article is an open access article distributed under the terms and conditions of the Creative Commons Attribution license (http://creativecommons.org/licenses/by/4.0/). 